\title{
SCHOPENHAUER, MESTRE DE NIETZSCHE: SOBRE NIILISMO E ASCETISMO
}

SCHOPENHAUER, MASTER OF NIETZSCHE: ABOUT NIHILISM AND

ASCETICISM

\author{
JOÃO CONSTÂNCIO ${ }^{1}$ \\ Universidade Nova de Lisboa - Portugal \\ joaoconstancio@fcsh.unl.pt
}

RESUMO: O artigo tentar mostrar três coisas: primeiro que, embora Nietzsche rejeite alguns dos aspectos mais importantes da famosa metafísica da vontade que se encontra no centro de toda a filosofia de Schopenhauer, tal metafísica não deixa por isso de ser o ponto de partida da sua análise do "facto fundamental da vontade humana" na Genealogia da Moral; depois, que o modo como Schopenhauer entende o ascetismo e a "negação da vontade" tem uma importância crucial para a compreensão da concepção nietzschiana do "ideal ascético" e de uma "vontade do nada" como vontade ascética; por fim, que a interpretação daquilo a que Nietzsche chama "niilismo" na Genealogia e, em geral, na sua obra não pode dispensar a reflexão sobre o modo como Nietzsche e Schopenhauer pensam o ascetismo e a ideia de uma "vontade do nada". Este último ponto implica a revisão crítica de importantes interpretações do niilismo em Nietzsche, como a de Stegmaier e a de van Tongeren.

PALAVRAS-CHAVE: Schopenhauer. Nietzsche. Vontade. Nada. Niilismo. Ascetismo.

ABSTRACT: The article tries to show three things: firstly, that although Nietzsche rejects some of the most important aspects of Schopenhauer's metaphysics of the will, this metaphysics is the point of departure of his analysis of the "basic fact of the human will" in his On the Genealogy of Morality; secondly, that Schopenhauer's view of asceticism and the "denial of the will" is crucial for the understanding of Nietzsche's conception of the "ascetic ideal" and an ascetic "will to nothingness"; thirdly, that the interpretation of what Nietzsche calls "nihilism" in the Genealogy and elsewhere cannot dispense with the interpretation of Nietzsche's and Schopenhauer's conceptions of asceticism in terms of a "will to nothingness". This last point leads to criticism of influential views of Nietzsche's conception of nihilism, such as Stegmaier's and van Tongeren's.

KEYWORDS: Schopenhauer. Nietzsche. Will. Nothingness. Nihilism. Ascetism.

\footnotetext{
${ }^{1}$ Professor Associado da Faculdade de Ciências Sociais e Humanas (FCSH) da Universidade Nova de Lisboa.
} 


\section{INTRODUÇÃO}

Trata-se neste texto de tentar mostrar três coisas: primeiro que, embora Nietzsche rejeite alguns dos aspectos mais importantes da famosa metafísica da vontade que se encontra no centro de toda a filosofia de Schopenhauer, tal metafísica não deixa por isso de ser o ponto de partida da sua análise do "facto fundamental da vontade humana" na Genealogia da Moral (GM III 1 e 28); depois, que o modo como Schopenhauer entende o ascetismo e a "negação da vontade" tem uma importância crucial para a compreensão da concepção nietzschiana do "ideal ascético" e de uma "vontade do nada" (GM III 14 e 28) como vontade ascética; por fim, que a interpretação daquilo a que Nietzsche chama "niilismo" na Genealogia e, em geral, na sua obra (pelo menos, na obra publicada) não pode dispensar a reflexão sobre o modo como Nietzsche e Schopenhauer pensam o ascetismo e a ideia de uma "vontade do nada". O Terceiro Ensaio da Genealogia da Moral, de Nietzsche, e o Livro IV de O mundo como vontade e representação, de Schopenhauer, serão os fios condutores deste texto. A minha preocupação implícita - ao longo de todo o texto - será a de tornar claro que, mesmo num texto tardio como a Genealogia, Schopenhauer permanece, para Nietzsche, o seu "educador", o seu "mestre". ${ }^{2}$

\section{I "O facto Fundamental da VONTADE HUMANA"}

Em Para a Genealogia da Moral, Nietzsche afirma ter identificado "o facto fundamental da vontade humana" (die Grundthatsache des menschlichen Willens, GM III 1, KSA 5.341). E aí escreve que esse "facto fundamental da vontade humana" é "o seu horror vacui [horror ao vácuo]: ela [a vontade humana] precisa de uma meta - e antes prefere querer o nada [das Nichts] a não querer nada” (GM III 1). Comecemos por investigar as raízes desta ideia no Livro IV de $O$ mundo como vontade e representação, de Schopenhauer.

Também para Schopenhauer a vontade humana tem um horror natural ao nada, um horror que resulta do facto de a vontade humana ser a vontade de um organismo que quer viver - ou, nos termos da metafísica de Schopenhauer, do facto de a vontade humana ser uma individuação corpórea da Vontade e, enquanto tal, ter horror ao nada simplesmente porque é "vontade-de-viver", "vontade de vida" (Wille zum Leben), uma vontade de se afirmar a si própria e de viver egoisticamente como espécime da espécie a que pertence: "Que temos um tão

\footnotetext{
${ }^{2}$ Em textos anteriores, procurei mostrar que o mesmo vale para a influência de Schopenhauer sobre o modo como o Nietzsche da maturidade pensa a superficialidade da consciência e a modalidade, ou estatuto epistémico, dos juízos filosóficos: cf., respectivamente, Constâncio (2011 e 2013b). Cf. também Constâncio/ Sousa (2014) em defesa de uma abordagem semelhante nos escritos de Salaquarda (1973 e 2007). Como exemplos perfeitos da menorização da influência de Schopenhauer em Nietzsche, Salaquarda refere as interpretações clássicas de Jaspers, Löwith e Heidegger. Mais recentemente, May (1999) e Leiter (2015) são bons exemplos de tal menorização (ou mesmo omissão) na análise das conceitos de ascetismo e de valores morais na Genealogia. Por contraste, Janaway (2007) procurar destacar a presença de Schopenhauer na Genealogia e, mais genericamente, no pensamento de Nietzsche na fase da sua maturidade. Note-se, por fim, que o presente artigo é uma versão revista, corrigida e aumentada do meu artigo sobre a relação entre Schopenhauer e Nietzsche publicado em The Palgrave Schopenhauer Handbook (Constâncio 2017).
} 
grande horror [ou: aversão] ao nada é simplesmente outra maneira de se dizer que temos uma tão grande vontade de viver" (WWV I \$71, p. 486). Ora, o facto de a mortalidade ser uma das condições da nossa individuação num organismo vivo isto é, o facto de a nossa vida nos ser dada como uma jornada finita entre o nascimento e a morte, entre o nosso passar a ser e a dissolução no nada - força a nossa vontade-de-viver a empreender "uma constante luta pela existência (ein steter Kampf um diese Existenz)” (WWV I \$57, p. 368) - a qual é, na verdade, uma luta contra o nada, contra o vácuo.

É a esta luta que Schopenhauer chama "o peso da existência (die Last des Daseins)" (WWV I $\$ 57$, p. 369). Mas este peso tem duas dimensões diferentes, que são, porém, igualmente fundamentais.

Primeiro, a existência é um peso para nós porque ela é "uma morte sempre adiada" (WWV I 557, p. 367), e isso faz que vivamos num constante "medo da morte" (WWV I 557 , p. 369). Toda a nossa vida tende a consistir numa activa, embora essencialmente inconsciente, "fuga da morte" (WWV I \$57, p. 369): ao querermos a vida (ao sermos "vontade-de-viver"), passamos o tempo a fazer tudo para evitar tanto a morte, quanto o mero pensamento da morte. Vivemos, em suma, num constante horror vacui, e isso dá um enorme peso à nossa existência.

Mas, em segundo lugar, a existência é um peso para nós porque por vezes (ou até demasiadas vezes) não conseguimos fugir da experiência do vácuo e experimentamo-lo, por assim dizer, directamente ou enquanto tal - e já não no modo da fuga. É isso que acontece quando os nossos desejos são satisfeitos. Se não encontramos imediatamente novos objectos de desejo ou se, como Schopenhauer diz, por um momento nos tornamos "seguros da nossa existência", então "não sabemos o que fazer com ela" (WWV I \$57, p. 369). A satisfação dos nossos desejos deixa-nos sem nada para querer. Ficamos sem metas, objectivos, propósitos que possamos perseguir. Numa tal situação, "apenas a pressão da vontade permanece” (WWV I \$65, p. 430), e por isso a única coisa que nos move é o peso da existência enquanto tal: "[...] a segunda coisa que faz as pessoas moverem-se [além da "fuga da morte" ou, o que é o mesmo, além da "aspiração à existência"] é o esforço por se livrarem do peso da existência, por deixarem de o sentir, por 'matar tempo', i.e., por escapar do tédio” (WWV I 557, p. 369).

Segundo Schopenhauer, este facto mostra que a vontade ela própria não tem "um propósito e objecto últimos", não tem "uma meta última (Ziel), nem um fim (Zweck) último" (WWV I \$56, p. 364) — que o nosso querer é "uma constante aspiração sem meta e sem repouso" (ein beständiges Streben, ohne Ziel und ohne Rast, WWV I \$57, p. 367). ${ }^{3}$ A vontade humana aspira a alcançar metas particulares e age segundo propósitos ou fins - ou, noutros termos, é movida por "motivos" —, mas apenas na medida em que a sua individuação, a sua existência num corpo particular, a faz lidar com o mundo. Enquanto "vontade-de-viver" particular, a vontade é "direccionada" para certas metas mundanas (WWV I \$66, p. 435), e "exprime o seu carácter" ao agir de acordo com determinados propósitos em vez de outros (e.g. WWV I \$55, pp. 342ss.). Mas "em si mesma” a vontade humana é

${ }^{3}$ Cf. também: WWV I \$29, \$57, \$58; WWV II xxviii. 
um mero "aspirar", "almejar" (Streben) — uma aspiração "cega", "inconsciente", que não tem uma direcção definida e, portanto, não tem "um propósito e objecto últimos", não tem "uma meta última (Ziel), nem um fim (Zweck) último". A visão schopenhaueriana da vontada não é teleológica: o que Schopenhauer sustenta é justamente que a vontade humana não tem um telos, não tem um fim último que quisesse alcançar, e no qual pudesse encontrar uma satisfação perfeita e definitva - ou, nas palavras de Schopenhauer, "nenhum fim alcançável pode pôr termo" ao almejar da vontade humana (WWV I \$56, p. 364). É por isso que a vontade humana é insaciável, "uma sede sem fim" (WWV I \$57, p. 367): “em nenhuma parte há uma satisfação final, em nenhuma parte um ponto de repouso" (WWV I \$56, p. 364).

É também por isso que, no tédio, somos confrontados com o "vazio" (WWV I \56, \58, \65) - o vazio da nossa própria vontade, "o vazio da vontade desocupada” (WWV I \$39, p. 240), e correlativamente o vazio de um mundo que se tornou um nada para nós porque não consegue agora oferecer-nos quaisquer motivos, propósitos ou metas a que possamos aspirar.

Em alguns passos importantes, Schopenhauer descreve este confronto com o vazio e o nada como um confronto com a falta de sentido da vida humana. Por exemplo: "É realmente incrível como a vida da grande maioria dos seres-humanos flui sem sentido e sem significado [nichtssagend und bedeutungsleer] quando vista de fora, e como é maçadora e irreflectida quando sentida por dentro. Não é senão um cansativo almejar e preocupar-se, um cambalear como se em sonhos pelas quatro idades da vida até alcançar a morte - tudo isto acompanhado por uma série de pensamentos triviais. Tais vidas são como relógios a que se dá corda e se movem, mas sem saber porquê" (WWV I 158, p. 379)”. Na nossa experiência do tédio, somos confrontados precisamente com esta falta de sentido. Mas o que significa "falta de sentido"? E como justifica Schopenhauer esta tese da "falta de sentido" da vida humana?

De certa forma, a metafísica da vontade em Schopenhauer não é outra coisa senão a expressão metafísica da falta de sentido da vida humana - na verdade, da "existência em geral". Já a tese de que a vontade é um aspiração sem meta e sem fim último exprime tal idea, pois "a vontade" designa aqui uma vontade nãoindividuada, "universal", que é pensada por Schopenhauer como o fundamento último da realidade no seu todo. Portanto, o que aquela tese sustenta é que, "em si mesma", a realidade é uma totalidade a que falta uma meta e um propósito uma totalidade sem sentido. Além disso, o que tal tese sustenta é que, sendo esse o fundamento último de toda a realidade, a individuação da vontade numa multiplicidade virtualmente infinita de corpos no espaço e no tempo resulta num conflito ou luta de todos contra todos que não serve qualquer propósito supra partes (e.g., WWV I 656, p. 354). A falta de sentido desta luta é particularmente conspícua na vida dos seres humanos, visto que aqui a consciência e a razão a tornam especialmente dolorosa (WWV I 556, pp. 354-355; WWV II xli, pp. 561ss.). Se há algum tipo de finalidade na natureza, é apenas na medida em que todos os organismos individuais são espécimes que servem os propósitos das suas espécies, isto é, estão, por assim dizer, programados para se reproduzirem e, portanto, para 
preservarem a sua espécie. Mas isto significa precisamente que "o indivíduo não tem valor para a natureza" (WWV I $\$ 54$, p. 325), "o indivíduo não é nada para ela" (WWV I \$60, p. 389): a natureza usa os organismos individuais como meios para os seus fins, e é portanto muito mais como um demónio do que como um deus (WWV II xxviii, p. 398). Dado que a existência das espécies não serve qualquer propósito ulterior e último, a natureza é meramente "um mundo de seres permanentemente carentes, que só conseguem durar algum tempo na medida em que se devoram uns aos outros, e que atravessam as suas vidas dominados pelo medo e a necessidade, e que frequentemente suportam terríveis aflições — até caírem nos braços da morte" (WWV II xxviii, p. 398).

Mais há algo mais que deve ser dito sobre a noção de sentido — ou de falta de sentido - na filosofia da vontade em Schopenhauer. Na medida em que os seres humanos têm uma "razão" (Vernunft) acontece não apenas que eles têm consciência da sua situação, mas também que são capazes de compreender conceptualmente a sua finitude e o peso da sua existência, tal como, portanto, a falta de valor que tal existência tem no meio de uma natureza a que falta um fim último. E esta circunstância gera neles uma necessidade que os outros animais, sendo destituídos de razão, não têm - a "necessidade metafísica", como Schopenhauer lhe chama (WWV II xvii; PP II, p. 364). Os seres humanos caracterizam-se por sentirem necessidade de "decifrar" o "enigma do mundo", necessidade de dar sentido à existência em geral e no seu todo - necessidade de encontrar o significado da "coisa em si" escondido por detrás dos fenómenos (um significado que se pressupõe dever ter, em última instância, a natureza de um "porquê"). Sem isso, sentem-se perdidos, ou seja: não conseguem deixar de se confrontar com o nada que são - e a que têm horror. Tal necessidade é a origem não só da metafísica (i.e. da filosofia), mas também da religião, e distingue o ser humano de todos os outros animais como o "animal metaphysicum" (WWV II xvii, p. 176; PP II, p. 364).

Ora, tudo isto está pressuposto na Genealogia da Moral, de Nietzsche. Muito especialmente o último capítulo do Terceiro Ensaio (GM III 28) pode ser lido como um comentário à concepção schopenhaueriana da vontade humana - um comentário no qual Nietzsche reformula e reinterpreta essa concepção dando ênfase, justamente, à ideia de sentido e de uma necessidade humana de sentido. Não há dúvida de que Nietzsche rejeita a metafísica na qual Schopenhauer enquadra a sua concepção da vontade humana - e abandona, em particular, a ideia de que cada vontade individual seja apenas uma manifestação e individução, ou um "fenómeno", de uma vontade universal ("a Vontade"). Mas não deixa por isso de basear a sua concepção da vontade humana - como concepção naturalizada, psicológica, pós-metafísica - na concepção não-teológica da vontade humana que, como vimos, encontramos em Schopenhauer. A sua ideia principal é a de que o horror da vontade humana ao nada é sinónimo de um horror à falta de sentido.

Veja-se o que Nietzsche escreve em GM III 28. A vontade humana, segundo sustenta, é uma vontade que precisa a cada momento de ser "salva" nomeadamente, salva de não conseguir "querer algo" (GM III 28, KSA 5.412) e, 
por consequência, salva de ceder a um "niilismo suicidário" (GM III 28, KSA 5.411). O vácuo, ou o nada, a que ela tem horror está sempre presente - precisamente nos termos descritos por Schopenhauer na sua análise do tédio e do "vazio da vontade desocupada” (WWV I \$39, p. 240). E o vácuo ou o nada a que vontade humana tem horror está sempre presente porque nenhuma meta lhe é dada a priori - ou seja, porque a vontade humana não tem um telos intrínseco. De forma a poder querer numa dada direcção e a agir de um determinado modo, ela precisa de criar as suas metas ou propósitos, ou seja, precisa de criar sentido. A vontade humana age de acordo com o princípio de que "qualquer sentido é melhor do que não haver sentido algum" (GM III 28, KSA 5.411). No seu horror ao nada, a vontade humana aspira por uma meta em geral - por qualquer sentido que lhe permita preencher "o vazio tremendo" (GM III 28, KSA 5.411) que, de outro forma, a avassala.

Para que melhor se compreenda tudo isto, é, porém, necessário que se considere o tema da vontade ascética em Nietzsche - e, primeiro, em Schopenhauer.

\section{A VONTADE ASCÉTICA}

Schopenhauer vê o ascetismo como um desenvolvimento do "amor puro" - o qual, segundo crê, não é nada senão a identificação e o cuidado com o sofrimento de outrem, ou seja, o mesmo que a "compaixão", a "piedade" (Mitleid). ${ }^{4}$ Para Schopenhauer, a compaixão implica sempre um certo grau de desindividuação, uma transição do egoísmo para o cuidado altruísta, desinteressado com outrem, na verdade um sentimento de ser uno com outrem, ou de encontrar no outro, em particular no seu sofrimento, "eu mais uma vez (Ich noch ein Mal)” (GrM §22, pp. 272-275). Em última análise, a individuação é uma ilusão, "mero fenómeno", de tal modo que todo o conflito entre vontades individuais não é senão um conflito entre manifestações de uma mesma vontade universal. Quando um indivíduo prejudica outro, o que acontece é que uma mesma vontade "crava os seus dentes em si própria" - pois no reino das coisas em si mesmas "aquele que atormenta e aquele que é atormentado são um só" (WWV I \$63, p. 419, p. 416-421; §65, p. 465; §66, p. 441; §70, p. 478). A compaixão surge, portanto, desta nossa capacidade de reconhecer a identidade fundamental entre nós próprios e um outro; e o ascetismo desenvolve-se a partir da compaixão porque resulta do sentimento de que, por mais vitorioso que seja aquele que atormenta outrem, também a sua vida é dor, como toda a vida - e, ao mesmo tempo, por mais oprimido que seja aquele que é atormentado, ele é ainda uma vontade-de-viver individuada num organismo e, portanto, é feito da mesma aspiração egoísta que o seu atormentador: "O primeiro [aquele que atormenta] erra se pensar que não partilha a dor do segundo, e este erra se pensar que não partilha a culpa daquele" (WWV I \$63, p. 419). Quanto mais uma pessoa compassiva tomar sobre os seus ombros "a dor do mundo inteiro" (WWV I \$68, p. 464), interiorizando não apenas que "a vida é toda ela sofrimento" (WWV I \$56, p. 366; \$59, p. 381-383;

${ }^{4}$ Cf. WWV I \$\$66-67. 
$\$ 65$, p. 429-431), mas também que todo o indivíduo é, pelo mero facto da sua individuação, culpado de egoísmo, tanto mais a compaixão de tal pessoa se tornará "amor ao próximo com uma completa negação de todo o amor de si" (WWV I \68, p. 459). A compaixão enquanto mit-leiden, isto é, como uma identificação com (mit-) o outro e o seu sofrer (leiden), é a estrada que conduz ao desprezo por si próprio, e o desprezo, ou aversão, por si próprio é a estrada que conduz ao ascetismo.

Para Schopenhauer, o ascetismo é, portanto, uma "negação do amor de si" motivada pela compaixão, e por isso é uma verdadeira "mortificação da vontade" (WWV I \$68, p. 451, p. 452-453, p. 463). Esta mortificação depende do desenvolvimento de uma "forte aversão" à nossa "natureza interna" (WWV I \$68, p. 449), ou seja, à vontade que se encontra individuada em cada um de nós. O ascetismo é, portanto, um "quebra deliberada da vontade por meio de uma recusa do agradável e uma procura do desgradável, o modo de vida da penitência voluntária e da auto-flagelação” (WWV I \$68, p. 463). Isto explica por que razão o ascetismo é, segundo Schopenhauer, tão diferente do suicídio: quem decide matarse "quer a vida, e está apenas insatisfeito com as condições em que ela lhe é dada" (WWV I §69, p. 471), mas "a essência da negação consiste em recusar os prazeres da vida, não o seu sofrimento” (WWV I \$69, p. 471), e só o ascetismo, ao contrário do suicídio, é, portanto, "negação da vontade-de-viver" (WWV I \$68, p. 452-453; $\$ 69$, p. 471). O ascetismo recorre ao "jejum e até à mortificação e à auto-tortura" (WWV I §68, p. 451), mas qua "negação da vontade-de-viver" é muito mais do que isso. A aspiração última do asceta é a sua própria abolição ou cancelamento (Aufhebung), o seu regresso ao não-ser, ao nada, Nichts, nihil (WWV I §54, p. 336; \$69, p. 474; \$71, p. 484-487). Schopenhauer daria, sem dúvida, a sua aprovação à fórmula que Nietzsche achou para designar a vontade ascética: uma "vontade do nada". Quando se torna ascética, a vontade tem o nada como meta - quer o nada enquanto tal.

Como é bem sabido, Schopenhauer vê o alcançar desta meta — ou seja, a real abolição da vontade, a sua dissolução no nada - como sendo a "santidade", e portanto como uma salvação mística e uma redenção do ser-humano. Além disso, crê que a santidade se funda num conhecimento (WWV I \$54, p. 336; \$69, p. 474). A estrada que vai da compaixão ao ascetismo e à abolição da vontade é a estrada na qual um indivíduo adquire conhecimento da essência ou natureza interna do mundo, e na verdade um conhecimento que não é meramente abstracto, mas sim intuitivo, afectivo, e praticado em acções, não em palavras. Trata-se do conhecimento pessimista que foi referido acima: o conhecimento de que a vida é dor, de que a individuação é um mal, de que "aquele que atormenta e aquele que é atormentado são um e o mesmo", de que "a individualidade é na realidade apenas um erro particular, um passo em falso, algo que era melhor que não fosse" (WWV II xli, p. 563) - e, em última análise, o conhecimento de que o mundo no seu todo é algo que "não devia ser" (WWV II xlvi, p. 664), ou de que "a existência deve certamente ser considerada um erro ou engano", que "era melhor para nós que não existisse" (WWV II xlviii, p. 695). Todo este conhecimento, note-se, diz respeito às coisas em si mesmas (ou à "coisa-em-si"). Na verdade, todas aquelas 
diferentes proposições apenas articulam diferentes aspectos de um só pensamento - o pensamento que constitui o conteúdo de toda a metafísica da vontade de Schopenhauer (WWV I \$53, p. 320). Só este conhecimento permite à vontade ascética alcançar aquilo a que aspira: a sua própria abolição, o seu regresso ao nada (WWV I \$54, p. 336; \$68, p. 452-453; \$69, p. 474; \$71, p. 484-487).

Sublinhe-se (e, como se verá adiante, é realmente importante sublinhar este ponto) que, para Schopenhauer, o querer que move a auto-abolição da vontade é, ao mesmo tempo, um querer a abolição do mundo. Aquilo a que chamamos "mundo" é "o espelho da vontade", de tal modo que "nós mesmo somos esta vontade e este mundo", e "a negação, abolição, reversão da vontade são também a abolição e desaparecimento do mundo, que é o seu espelho" (WWV I \$71, p. 485). Noutros termos, o "mundo" é, para Schopenhauer, o que a vontade representa como sendo a realidade espácio-temporal na qual persegue metas particulares, de tal forma que o aspirar da vontade ao não-ser é, ao mesmo tempo, o seu aspirar ao não-ser desssa realidade espácio-temporal, o mundo. É por isso que o "nada" (Nichts) em causa no ascetismo é "essencialmente relativo", um "nihil privativum" que "se refere a um algo determinado que ele nega" (WWV I \$71, p. 484) - algo determinado que "é justamente o mundo como representação" (WWV I \$71, p. 485). A negação ascética da vontade é, ao mesmo tempo, negação do mundo - ou, como Schopenhauer escreve na última frase do seu magnum opus, "para aqueles cuja vontade se voltou do avesso e se negou a si própria, este nosso mundo real, com os seus sóis e galáxias, é — nada” (WWV I §71, p. 487).

Mas consideremos agora a concepção do ascetismo em Nietzsche. A que ponto é semelhante à de Schopenhauer? E exactamente em que ponto e de que modo se afasta da de Schopenhauer?

Tal como se indicou acima, Nietzsche vê o ascetismo como expressão de uma "vontade do nada" (GM III 14 e 28). A vontade ascética tem o nada como meta, objectivo, fim; a vontade ascética toma a sua própria abolição e a abolição do mundo como o propósito das suas acções. Obviamente, ao fazer isso não chama "nada" ao nada: habitualmente, "não se diz 'nada': em vez disso, diz-se 'o além'; ou 'Deus'; ou 'a verdadeira vida'; ou nirvana, salvação, santidade..." (AC 7).5 Até certo ponto, é também esta a visão de Schopenhauer, pois também ele pensa que "Deus" e "nirvana" são apenas dois nomes que as duas religiões mais profundas - o Cristianismo e o Budismo - dão ao "nada"; e foi também Schopenhauer quem primeiro argumentou que a razão por que os santos e os místicos do Cristianismo e do Budismo descrevem as suas acções como "salvação" e "santidade" é que aquilo que alcançam (ou julgam alcançar) através do ascetismo é a dissolução da sua vontade no nada (WWV I \$59, p. 384; \$63, p. 420-421; \$68, p. $352-471 ; \$ 70$, p. $480-483$; $\$ 71$, p. $484-487){ }^{6}$

A primeira grande diferença entre a visão de Nietzsche e a de Schopenhauer é, porém, que, para o primeiro, nada disto é matéria de conhecimento: não é a verdade que dirige os santos e os místicos para o nada. O que os faz querer o

${ }^{5}$ Cf. também GM III 1 e GC Prefácio 3.

${ }^{6}$ Para uma discussão recente des tema, cf. Janaway (2017). 
nada é apenas a sua necessidade de sentido. Este é o cerne do aparente paradoxo que Nietzsche formula em GM III 1 e 28. O que faz os santos e os místicos quererem o nada é... o seu horror ao nada, o horror vacui que é o traço fundamental da vontade humana. O ascetismo aparece - a vontade humana tornase uma vontade ascética - porque, em situações extremas nas quais a vontade humana é prolongadamente confrontada com o nada e se vê incapaz de encontrar objectos de desejo (ou seja, de ver quaisquer metas como tendo sentido), tende a conseguir salvar-se ainda através de um expediente que consiste em transformar $O$ próprio nada numa meta, num objecto de desejo. O ascetismo é o derradeiro mecanismo de defesa da vontade humana, um expediente instintivo que ela usa, como último recurso, para se salvar do "niilismo suicidário". Transformar o próprio nada numa meta é suficiente para salvar a vontade humana e fazê-la "querer algo" (GM III 28, KSA 5.412). É isto que Nietzsche quer dizer quando sustenta que o horror vacui da vontade humana é tão intenso que "ela prefere querer o nada a não querer nada" (GM III 28, KSA 5.412; GM III 1, KSA 5.339), e que a vontade ascética, a "vontade do nada", é "uma aversão à vida, uma rebelião contra os pressupostos mais fundamentias da vida — mas é e continua a ser uma vontade..." (GM III 28, KSA 5.412).

Esta vontade ascética, a "vontade do nada", é a base daquilo a que Nietzsche chama na Genealogia "o ideal ascético". O "ideal ascético" é o desenvolvimento civilizacional, cultural, histórico daquele mecanismo de defesa básico e instintivo - o qual, como acabámos de ver, consiste em transformar o nada de objecto de aversão em objecto de desejo. Tal desenvolvimento civilizacional constrói diferentes estruturas de sentido - ou seja, sistemas abertos de valores e propósitos (como o Platonismo, o Cristianismo, o Budismo) - que oferecem respostas a perguntas (a "porquês") como, por exemplo, "porquê, de todo, o ser-humano?", ou "porquê o meu sofrimento?" (GM III 28, KSA 5.411). Diferentes respostas ascéticas a estas perguntas são diferentes formas de estatuir o nada como meta da vontade humana. Assim, por exemplo, o Platonismo desenvolve uma versão particular do ideal ascético porque estabelece como meta alcançar um "mundo verdadeiro" de conhecimento absoluto através da superação dos sentidos, da percepção, do corpo, basicamente de tudo o que faz do conhecimento humano um conhecimento condicionado, finito, relativo; o Cristianismo, por seu lado, estabelece como meta alcançar a "verdadeira vida" do amor altruísta através da superação do egoísmo, da sexualidade, da animalidade, etc. Note-se como, em ambos os casos, a meta é a fuga em direcção ao nada (ao "mundo verdadeiro", à "vida verdadeira") através de uma progressiva negação deste mundo. Uma vontade ascética como vontade do nada não pode deixar de envolver auto-aversão incluindo, obviamente, aversão ao nosso corpo-próprio enquanto encarnação da nossa vontade individual (tal como Schopenhauer sublinhou - com aprovação); mas a auto-aversão ascética não pode deixar de envolver também ódio e negação de tudo o mais que é terreno - negação de todo o horizonte onde se joga a acção da vontade humana, negação deste mundo. Assim,

é absolutamente impossível continuarmos a esconder o que de facto se exprime em todo o querer que tenha recebido o seu direccionamento do ideal ascético; o ódio contra o que é humano, 
mais ainda contra o que é animal, mais ainda contra o que é material, o horror perante os sentidos, perante a própria razão, o medo perante a felicidade e a beleza, o desejo de fugir a tudo o que é aparência, mudança, devir, morte, aspiração ou até mesmo tudo o que seja desejo... (GM III 28, KSA 5.412).

Sublinhe-se a natureza ambivalente daquilo que Nietzsche aqui descreve. O desejo pelo nada e o ódio à vida que estão em causa no querer ascético resultam dos seus opostos - isto é, do horror vacui e do amor à vida (ou da "vontade-deviver") - e, na verdade, servem estes opostos: tal desejo e tal ódio vicejam porque oferecem orientação e propósito - oferecem sentido - no mundo que eles negam. Assim, por exemplo, o ideal ascético promove o ódio à vida que é característico das vontades humanas oprimidas, mas também "salva" estas vontades: "para os indivíduos fisiologicamente mal formados e para os desequilibrados (ou seja, para a maioria dos mortais), [os ideias ascéticos são] uma tentativa de eles se apresentarem como 'demasiado bons' para este mundo, uma forma sagrada de libertinagem, a sua melhor arma na luta que travam com a dor lenta e o tédio" (GM III 1). E algo semelhante vale para o sacerdote ascético, bem como para os santos e os místicos descritos por Schopenhauer: "no caso dos padres, os ideais ascéticos significam a fé sacerdotal propriamente dita, o seu melhor instrumento de poder e também a 'suprema' autorização para o exercício desse poder. Finalmente, para os santos, um pretexto para a hibernação, a sua novissima gloriae cupido, a sua paz no nada ('Deus'), a sua forma de demência". (GM III 1). Estes exemplos tornam claro em que sentido a vontade do nada é "uma aversão à vida, uma rebelião contra os pressupostos mais fundamentias da vida; mas é e continua a ser uma vontade..." (GM III 28).

E estes exemplos também tornam claro que a avaliação nietzschiena da vontade do nada é oposta à de Schopenhauer. A famosa "transvaloração de todos os valores" é, em grande medida, uma reavaliação do ascetismo e do ideal ascético. Contudo, mesmo que esteja aí em causa a inversão (ou, pelo menos, a transformação radical) da posição axiológica de Schopenhauer, isso mesmo mostra, de novo, quão importante permanece Schopenhauer no pensamento maduro de Nietzsche. Na verdade, da comparação entre as posições de Nietzsche e as de Schopenhauer sobre a vontade ascética na Genealogia e no Livro IV do Mundo como vontade e representação podemos concluir que a análise schopenhaueriana deu a Nietzsche a chave (ou, no mínimo, uma das principais chaves) para a interpretação de toda a história da cultura ocidental. Nietzsche nega que o ascetismo tenha como fundamento um conhecimento acerca da condição humana, mas concorda com Schopenhauer em que o ascetismo (a vontade do nada) é o cerne escondido do Platonismo, do Cristianismo, do Budismo e (pelo menos em certa medida) também do pessimismo grego, romano e helenístico. Pois, como é bem sabido, Nietzsche declara que o ideal ascético foi o único ideal que a humanidade teve "até agora" — o único remédio da humanidade contra o "niilismo suicidário" (GM III 28, EH GM). O ideal ascético foi "o 'faut de mieux" par excellence até agora" (GM III 28); foi sempre "o ideal prejudicial par excellence, uma vontade do fim, o ideal da decadência”, mas a razão por que 
adquiriu um "incrível poder" na história da humanidade foi o facto de que "nunca teve competição" - nunca houve um "contra-ideal' (EH GM).

Contudo, não é só na avaliação da vontade ascética que a posição de Nietzsche difere da de Schopenhauer. Também a análise psicológica da vontade do nada em Nietzsche é ligeiramente diferente da de Schopenhauer. A sua focagem na questão do sentido (Sinn) permite-lhe descobrir um pressuposto falso na psicologia de Schopenhauer. Esta psicologia é essencialmente hedonista: Schopenhauer pressupõe que aquilo que os seres-humanos desejam é, em última análise, o prazer ou a felicidade - a qual Schopenhauer intrepreta negativamente como preenchimento de uma falta, e portanto como a ausência de dor. ${ }^{7}$ Este pressuposto também está implicado na sua tese de que a natureza do querer humano determina que se seja sempre movido ou pelo peso da fuga à morte ou pelo peso do tédio: "embora na verdade toda a gente preferisse estar em repouso, a necessidade e o tédio são os chicotes que mantêm o pião em movimento" (WWV II xxviii, 410). Mas Nietzsche viu que, se aquilo que nos move realmente e em última instância é o sentido, então o hedonismo é uma tese problemática. O "incrível poder" do ideal ascético é ele mesmo uma prova de que aquilo que está em jogo na vida humana não é apenas o prazer e a dor — de tal modo que está longe de ser líquido que as pessoas queiram "repouso" e não precisamente o contrário disso: inquietação, movimento, acção. Se o prazer fosse a única motivação humana, por que razão alguém teria interesse num ideal que promove práticas dolorosas (incluindo a auto-tortura)? E como pode, em geral, alguém encontrar prazer na dor (uma ocorrência comum na vida humana)? O ideal ascético tem um "incrível poder" sobre os humanos porque providencia sentido. Dá origem a muito sofrimento, mas a um sofrimento no qual as pessoas encontram um propósito e, portanto, um sentido:

Se se ignora o ideal ascético, então o homem, o animal homem, não teve até hoje qualquer sentido, a sua existência sobre a terra não teve qualquer meta. "Para quê o homem"? Eis uma pergunta que não tinha resposta. Faltava a vontade para o homem e para a terra. Por trás de cada grande destino humano ouvia-se sempre como refrão um ainda maior "em vão!". É precisamente isso que o ideal ascético significa, que faltava qualquer coisa, que o homem estava envolvido por uma tremenda lacuna... Incapaz de se justificar, de se explicar, de afirmar-se ele mesmo, o homem sofria com o problema do seu sentido. Sofria também com outras coisas, no fundamental era uma animal doentio: mas o seu problema não era o sofrimento em si, mas antes o facto de não obter resposta para o seu grito interrogativo: "sofrer para quê?" O homem, o animal mais corajoso e mais habituado a sofrer, não nega o sofrimento em si: quere-o, procura-o ele mesmo, com a condição de que alguém lhe mostre um sentido para isso, um para quê do sofrer.A falta de sentido do sofrimento - e não o sofrimento foi a maldição que até hoje pesou sobre a humanidade... e o ideal ascético oferecia-Ihe um sentido! (GM III 28, KSA 5.411). ${ }^{8}$

\footnotetext{
7 Cf. WWV I \$56-\$57.

${ }^{8}$ Sobre a conexão entre este ponto importante da psicologia de Nietzsche e a hipótese da "vontade de poder", cf. Soll (1998) e Reginster (2006).
} 
A principal ideia deste texto fundamental é suficientemente clara. A razão por que os seres humanos têm um sentimento tão agudo do "peso da existência" não é porque sofrem, mas sim porque precisam de que o seu sofrimento tenha um sentido; o ideal ascético foi até hoje o único ideal porque foi até hoje a única interpretação do sofrimento de que os humanos foram capazes - a única forma que encontrámos de ver um propósito no sofrimento. Portanto, mesmo que, como Schopenhauer sustenta, "toda a vida seja sofrimento", isso não justifica, por si mesmo, uma negação ascética da vontade, uma negação pessimista da vida. A vida poderia ser muito dolorosa e, ainda assim, fazer sentido - e, portanto, não haver razão para a negar. A inferência "a vida é dolorosa, logo não tem valor e não devia existir" não é válida.

Mas, se queremos ter uma visão mais completa da influência de Schopenhauer sobre a concepção da vontade humana na obra de Nietzsche, e se queremos, em particular, compreender as consequências de tal influência na concepção nietzschiana do niilismo, devemos considerar ainda (embora muito sucintamente) dois temas fundamentais: primeiro, a relação entre o ideal ascético e a moral; segundo, a relação entre o ideal ascético e a metafísica.

\section{A MORAL E A METAFÍSICA}

Para Schopenhauer, o ascetismo é um atitude moral. A negação ascética da vontade desenvolve-se a partir da compaixão e, como se observou acima, implica o reconhecimento não só de que o outro é "eu de novo", "eu mais uma vez", mas também de que todo o indivíduo qua indivíduo é "culpado" - culpado do seu egoísmo. Este sentimento de culpa, aliado ao sentimento de que a vida é dor, é o que espoleta a auto-aversão (ou "a negação de todo o amor de si") em que assenta a negação ascética da vontade. Ora, neste quadro, pode dizer-se que a concepção schopenhaueriana de ascetismo tem dois pressupostos fundamentais. Em primeiro lugar, ao sustentar que há "culpa" no egoísmo, pressupõe que a distinção entre o bem e o mal consiste na distinção entre acções egoístas e acções altruístas. Como diz Schopenhauer, "a ausência de qualquer motivação egoísta é [...] o critério do valor de uma acção moral' (GrM \$15, p. 204). ${ }^{9}$ Em segundo lugar, ao sustentar que se justifica que uma pessoa se torne um místico ou mesmo um santo, Schopenhauer pressupõe que há factos morais, de tal modo que a perspectiva da vontade ascética é uma perspectiva de conhecimento - nomeadamente, de conhecimento do bem (ou de factos morais, factos sobre o bem e o mal), e na realidade de um conhecimento do bem fundado num conhecimento da verdade sobre as coisas em si mesmas, ou seja, um conhecimento metafísico. Esta é a razão por que Schopenhauer considera que pode legitimamente dizer que o moralmente certo e o moralmente errado "são válidos também para a ordem natural das coisas e não são, de forma alguma, meramente convencionais" (WWV I \$62, p. 403). Se um indivíduo, movido pelo egoísmo e fazendo uso ou de violência ou da astúcia,

\footnotetext{
${ }^{9}$ Para Schopenhauer, uma acção é egoísta se "o seu fim último é o bem-estar e a dor daquele que age" (GrM §16, 206; cf. \$14); uma acção é altruísta se é "livre de todos os motivos egoístas" e "deseja o bem-estar de outrem" (GrM \$16, 210; cf. \$18).
} 
"afirma a sua própria vontade para além do seu corpo através da negação da vontade que aparece no corpo de outrem" (WWI I \$62, p. 394), a sua acção é realmente, e não apenas convencionalmente, condenável - errada do ponto de vista moral. Se, porém, é movido pela compaixão e age em conformidade com o princípio neminem laede ("não prejudiques ninguém"), então age de um modo que é justo (GrM \$17); e se a sua compaixão o faz ir mais longe e o leva a agir em comformidade com o princípio omnes quantum potes, juva ("ajuda todos quanto possas"), então a sua acção éboa, é moralmente certa e moralmente louvável (GrM §18; WWV I \$62).

Nietzsche concorda em que a perspectiva ascética é uma perspectiva moral. A moral pertence ao cerne do ideal ascético. A interpretação do sofrimento oferecida por este ideal deu um propósito moral à existência humana. Através do ideal ascético, a vida tornou-se uma tarefa moral - justamente a tarefa de se tornar "bom" por meio de práticas ascéticas que conduzam a que uma pessoa se liberte da sua natureza "malvada", moralmente má (do seu egoísmo, da sua finitude etc). Ao negar o mundo e ao afirmar o nada ("o além", ou "Deus", ou "a vida verdadeira", ou "o nirvana", ou "o mundo verdadeiro"), o ideal ascético fez o serhumano sentir-se "envergonhado de todos os seus instintos", na verdade "de si próprio" (GM II 7); com isso, "colocou todo o sofrimento sob a perspectiva da culpa" (GM III 28, KSA 5.411). Este facto "trouxe consigo mais sofrimento, um sofrimento mais profundo, mais interior, mais venenoso, mais destruidor da vida", mas foi justamente isto - a culpa, a moral, o propósito moral — que "salvou" a vontade humana, permitindo-lhe "querer alguma coisa": "não importava à partida para quê, porquê, com o quê o ser-humano queria: a própria vontade estava salva" (GM III 28, KSA 5.411-412).

Assim, toda a Genealogia da Moral pode ser lida como uma reacção à visão ascética da moral que Nietzsche encontrara na obra de Schopenhauer. O próprio Nietzsche sugere isso mesmo no Prefácio, quando conta que, já em Humano, demsiadamente humano, as suas reflexões sobre a origem da moral serviram o propósito ulterior, e mais importante, de investigar "o valor da moral". "Sobre isto", escreve, "tive de, praticamente sozinho, entrar em discussão com o meu grande mestre [ou professor] Schopenhauer, a quem esse meu livro, a paixão e a oculta contradição que é esse livro, se dirige, como se a um contemporâneo" (GM Prefácio 5). Em Humano, demasiadamente humano, a questão principal era "o valor do 'não-egoísmo' [ou: do que é altruísta, do altruísmo], dos instintos de compaixão, abnegação, sacrifício de si” - a questão de saber se tinha justificação a deificação destes fenómenos na obra de Schopenhauer (GM Prefácio 5). Mas na Genealogia a influência de Schopenhauer é ainda maior, pois todo o livro é uma investigação sobre a natureza ascética da moral. A "moral da compaixão" de Schopenhauer (cf. GM Prefácio 5 e 6) revelou a Nietzsche a natureza escondida da moral - a sua natureza ascética. Ou seja, revelou-lhe que a moral foi sempre determinada e movida por uma vontade do nada: fê-lo ver toda a história da moral como a história "do grande perigo para a humanidade, a sua mais sublime atracção e sedução - mas para onde? para o nada? - foi justamente aqui que vi o princípio 
do fim, a paragem, o cansaço que se põe a olhar para trás, a vontade que se volta contra a vida" (GM Prefácio 5).

Note-se que é desta perspectiva - a perspectiva da descoberta da natureza ascética da moral - que Nietzsche interroga "o valor dos valores morais" (GM Prefácio 6) e critica os dois pressupostos fundamentais da ética de Schopenhauer menciondos acima. Em primeiro lugar, deve ser claro que os três ensaios da Genealogia continuam o questionamento do "valor do altruísmo" já iniciado em Humano, demasiadamente humano. As genealogias de Nietzsche visam mostrar que o princípio segundo o qual "a ausência de qualquer motivação egoísta é [...] o critério do valor de uma acção moral' (GrM \$15, p. 204) tem, na verdade, origem no ressentiment de escravos (Primeiro Ensaio), na repressão social dos nossos instintos selvagens e na instituição da culpa através da socialização (Segundo Ensaio), bem como no ressentiment e desejo de poder terreno dos padres ascéticos (Terceiro Ensaio). Estas origens contam a história do ideal ascético, e portanto da vontade do nada enquanto vontade ascética. Em segundo lugar, é da perspectiva desta história da vontade do nada que, na Genealogia, Nietzsche rejeita a tese de que a moral resultaria de algum tipo de conhecimento do bem. Na verdade, porém, a rejeição mais clara desta tese é talvez a que ocorre no Crepúsculo dos Ídolos, onde Nietzsche escreve: "É conhecida a minha exigência de que os filósofos se posicionem além do bem e do mal - que tenham abaixo de si a ilusão do juízo moral. Esta exigência segue-se de uma evidência que fui o primeiro a formular: que não há factos morais" (CI Os 'aperfeiçoadores' da humanidade 1). Na Gaia Ciência proclama uma tese semelhante, talvez até de maior alcance: "qualquer que seja o valor do mundo que agora existe, não é um valor que ele tenha em si, segundo a sua natureza - a natureza é sempre sem valor: —esse valor foi-lhe dado, oferecido, e nós fomos os doadores e ofertantes!" (GC 301). Esta tese "antirealista" está implicitamente presente em todo percurso da Genealogia da Moral, e especialmente nos capítulos sobre a vontade humana e o seu traço fundamental, o horror vacui, o "preferir querer o nada a não querer nada". As avaliações morais resultam de um mecanismo de defesa que faz a vontade humana reagir ao vaccum da falta de sentido com a transformação do nada em meta do querer, ou objecto de desejo. Nós somos os "doadores e ofertantes" dos valores morais, nós damos e oferecemos estes valores a uma natureza que é sem valor, ou seja, que não tem finalidade, portanto não tem um valor intrínseco, independente de doações de sentido como a nossa - e damos e oferecemos tais valores inventando e projectando propósitos ou fins que nos permitem querer o próprio nada como uma meta. Os valores que criamos neste processo servem a nossa necessidade de sentido - mas isto significa que eles só existem por esta razão, e não como resultado de algum "conhecimento" sobre "factos morais".

Este estado de coisas implica que Nietzsche rejeite, a fortiori, a ideia de que possa haver algum tipo de conhecimento do bem fundado num conhecimento metafísico, isto é, num conhecimento último e absoluto sobre o que realmente existe - um conhecimento da verdade sobre as coisas em si mesmas, um conhecimento da "coisa-em-si". Na verdade, a partir de Humano, demasiadamente humano a sua rejeição da possibilidade desse tipo de conhecimento é muito clara. 
Por outro lado, e apesar desta rejeição fundamental da crença na possibilidade de uma metafísica, na Genealogia Nietzsche continuar a ter Schopenhauer como "mestre" e "educador", como o "grande professor" que lhe ensina como a moral e a metafísica estiveram sempre ligadas na história da cultura ocidental (na "Europa") - tão ligadas que a história do ideal ascético e das suas morais é, ao mesmo tempo, a história da metafísica.

Podemos compreender que assim é se nos debruçarmos mais uma vez sobre o último capítulo da Genealogia.

O modo como Nietzsche descreve a nossa necessidade de sentido evoca as reflexões de Schopenhauer sobre a "necessidade metafísica". Como vimos acima, Nietzsche entende a nossa necessidade de sentido como a necessidade de obter respostas para os "porquês" mais fundamentais da nossa condição: "porquê, de todo, o humano?", "porquê o meu, o nosso sofrimento?". Sem respostas a estas perguntas, os seres-humanos tendem a sentir que as suas vidas não têm sentido, ou são "em vão" (Umsonst, GM III 28, KSA 5.411); e tendem, muito particularmente, a sentir que o seu sofrimento é sem sentido, sem propósito, absurdo. Mas, implicitamente, Nietzsche nega precisamente que tenhamos uma tendência natural para fazer tais perguntas, nega que faça parte de uma suposta "natureza humana" fazer tais perguntas e ter a necessidade de obter respostas para elas. Este é um ponto em que Nietzsche se separa de Schopenhauer, nomeadamente quando sublinha que fazer tais perguntas e desenvolver respostas para elas é apenas algo que os seres-humanos fizeram "até agora" - é um facto histórico, não um facto natural. Mas, em todo o caso, o facto histórico é justamente este: que, "até agora", "até aqui", só houve um tipo de respostas àquelas perguntas - o tipo de respostas que podem ser dadas no quadro do ideal ascético - e estas respostas pressupõem que aquelas perguntas são metafísicas e requerem respostas metafísicas. Para Nietzsche, porém, uma proposição é metafísica e dá resposta a uma pergunta metafísica se pretende ser "incondicionada", isto é, se pretende estabelecer o que é X em última instância, o que é isto ou aquilo "em si mesmo". ${ }^{10} \mathrm{O}$ ideal ascético responde a "porquês" dando respostas que têm a pretensão de ser incondicionadas — ou, na terminologia de Schopenhauer, a pretensão de contribuir para que seja decifrado o "enigma do mundo" e descoberta a verdade sobre a "coisa em si".

Como podemos assegurar que Nietzsche vê as respostas ascéticas às perguntas por um porquê como respostas metafísicas? Primeiro, é bastante evidente que, para Nietzsche, tais respostas passam por uma dada interpretação do nada: todas elas pretendem falar-nos do nada como um "além", ou "Deus", ou "nirvana", ou, como Nietzsche diz com ironia em Para além do bem e do mal, "o regaço do ser, do não-transitório, do Deus escondido, da 'coisa em si'" (BM 2). Por outras palavras: as respostas ascéticas põem ou projectam a existência de uma realidade última, um "outro mundo" para lá dos fenómenos - e esse "outro mundo" é o "mundo verdadeiro", o mundo de uma verdade última, incondicional,

${ }^{10}$ Cf., por exemplo, NL 1883 8[25], KSA 10.342; veja-se a concepção da verdade metafísica como "verdade absoluta" e de verdades "incondicionais" ou "não-qualificada" em HH 2 e HH 630-636. 
metafísica. A vontade ascética, a vontade do nada pressupõe vontade de verdade - que é uma vontade metafísica.

E é por isso que Nietzsche vê a vontade de verdade como o "cerne" do ideal ascético (GM III 27, KSA 5.409). Tal como a Gaia Ciência torna claro, Niezsche pensa a vontade de verdade como uma vontade de uma verdade "platónica", por isso metafísica (GC 344). O ideal ascético é o ideal cujo cerne é a vontade de verdade porque esse ideal pressupõe que há verdades "incondicionais" que respondem às perguntas mais fundamentais e mais elevadas por um porquê da nossa existência e do nosso sofrimento. Ser movido por uma tal vontade de atingir verdades últimas e incondicionadas põe, i.e., projecta, um "mundo verdadeiro" que transcende o mundo fenoménico (cf. CI Fábula) - "afirma outro mundo que não o da vida, da natureza e da história” (GC 344). ${ }^{11} \mathrm{O}$ ideal ascético cria a metafísica como metafísica da transcendência, e as muitas formas desse ideal são as muitas formas que a metafísica da transcendência assumiu "até agora". Tais formas incluem também a "fé metafísica" que move a ciência moderna: a fé em que os seus progressos empíricos nos encaminham passo a passo para uma verdade absoluta, para a "coisa em si" (cf. GC 344, GM III 27). Na Gaia Ciência, Nietzsche estabelece esta conexão entre a vontade do nada e a vontade de verdade ao declarar que aqueles que "afirmam outro mundo" têm de "com isso negar o seu contraponto, este mundo, o nosso mundo", de tal modo que a vontade de verdade não é senão uma "oculta vontade de morte" (GC 344). Projectar para um plano transcendente um "mundo verdadeiro" implica embarcar numa negação ascética da vontade - e, tal como Schopenhauer ensinou, tal negação não pode deixar de ser, ao mesmo tempo, uma negação do nosso mundo.

\section{NIILISMO}

O que é exactamente o "niilismo" para Nietzsche? Uma forma possível de dar unidade ao que Nietzsche designa geralmente por "niilismo" consiste em defini-lo como o sentimento e a convicção de que a vida humana e, na verdade, o universo no seu todo não têm sentido. Alguém é "niilista" e tem "valores niilistas" (num plano que é sempre em parte afectivo, não apenas intelectual) ${ }^{12}$ se não vê um sentido na vida - um sentido que a englobe como um todo e, por assim dizer, lhe dê um propósito no universo. Nos seus primeiros escritos, Nietzsche não usa ainda o termo "niilismo", mas articula o sentimento da falta de sentido da vida nos termos de um sentimento do "absurdo da existência" (e.g., NT 7). Nos escritos póstumos da maturidade, a "falta de sentido" (Sinnlosigkeit) é geralmente explicada como "falta de metas" (Ziellosigkeit) e "falta de valor" (Werthlosigkeit). O sentimento de que a vida não tem sentido é o sentimento de que a vida não tem um valor intrínseco porque não tem uma meta ou propósito intrínseco - em última instância, porque a própria existência, "o mundo" (este mundo), não tem uma meta ou propósito intrínseco. Assim, o niilismo parece ser o que vem depois

\footnotetext{
${ }^{11}$ Note-se como em CI Fábula Nietzsche pensa a "verdade" e o "mundo verdadeiro" como sendo o mesmo que a "coisa em si".

${ }^{12}$ Cf. Pippin (2010), que argumenta que, para Nietzsche, o niilismo é "a failure of desire".
} 
da "morte de Deus" na alta modernidade. O "homem louco" que anuncia a morte de Deus na Gaia Ciência deixa-o bem claro: em resultado desta morte, o serhumano passará agora pela vida "como se através de um nada infinito" (GC 125). O ideal ascético — o único ideal que existiu até hoje - não fez mais do que mascarar um vácuo sem sentido, sem propósito, sem valor. ${ }^{13}$

De acordo com o que vimos acima, a metafísica da vontade em Schopenhauer exprime uma visão do universo, e em especial da vida humana e do sofrimento humano, como sendo uma realidade destituída de sentido, propósito e valor. O ser-humano tem, por natureza, uma "necessidade metafísica" porque o seu sofrimento não tem sentido e o universo é, na verdade, apenas a manifestação espácio-temporal de uma "vontade" que é um mero "almejar" (Streben) e não tem uma meta, fim, ou propósito último. Se a hipótese da "vontade de poder" em Nietzsche implica pensar o universo como uma pura multiplicidade de "reivindicações de poder" destituídas de um propósito último ("uma tirânica, brutal e impiedosa execução de reivindicações de poder”, BM 22), então essa hipótese não desenha um quadro do universo substancialmente diferente do quadro schopenhaueriano da natureza como uma constante e absurda "luta" entre forças que apenas exprimem o almejar cego e sem propísito da "vontade universal".

$\mathrm{Na}$ verdade, pode dizer-se que, no Livro V da Gaia Ciência, Nietzsche apresenta Schopenhauer - e não a si próprio ou ao homem louco do $\$ 125$ como o primeiro Europeu que proclamou "a morte de Deus". Schopenhauer foi "o primeiro ateu confesso e íntegro que nós Alemães tivemos", o primeiro que rejeitou "a mentira da fé em Deus". Esta rejeição foi o culminar de "dois mil anos de disciplina para a verdade" (GC 357) - o culminar do "heroísmo da veracidade" (CE IV, KSA 1.374) - e isso foi um "acontecimento europeu" porque Schopenhauer compreendeu que o colapso da mentira implicou perguntar, pela primeira vez na cultura europeia: "a existência tem, de todo, um sentido?' (GC 357)

Até certo ponto, a filosofia de Nietzsche é apenas uma radicalização do confronto de Schopenhauer com esta pergunta, isto é, com o niilismo - uma radicalização focada talvez em dois pontos principais: (a) a rejeição da moral do ideal ascético (isto é, de todos os valores ascéticos), e (b) a rejeição da metafísica.

(a) Segundo Schopenhauer, a descoberta fundamental da filosofia teorica de Kant - a de que o conhecimento é relativo à forma do nosso entendimento e, portanto, não há conhecimento das coisas em si mesmas - destruiu a metafísica como "teologia especulativa", e a destuição da "teologia especulativa" devia ter sido também o fim da "moral teológica", ou seja, da crença em que a ética pode ser um sistema de prescrições morais ou deveres fundados no conhecimento de "Deus". A ética kantiana é basicamente uma "auto-mistificação" que tenta manter vivo tudo aquilo que a Crítica da Razão Pura, na verdade, matou. ${ }^{14}$ Nietzsche concorda inteiramente com esta avaliação da obra de Kant (cf. GC 335), mas procura ir para além de Schopenhauer. Por um lado, fá-lo mostrando que, apesar

13 Tal como escreve Paul van Tongeren (2017: 298), o ideal ascético é apenas uma "estrutura protectora que foi construída para esconder o absurdo da vida e do mundo" (tradução nossa). Cf. também van Tongeren (2012: 83-133).

${ }^{14}$ Cf. GrM \$2, 111-112; \$3-\$11 (especialmente \$8); §12, 120; \$16,209. 
do ataque de Schopenhauer à "moral teológica", também este, como Kant, se mantém injustificadamente fiel ao cerne moral do Cristianismo. Mas, por outro, fálo adoptando o ponto-de-vista que, para Schopenaheur, era o do "anticristo" (PP II \$109, p. 214): o ponto-de-vista segundo o qual não há um "sentido moral" no universo, apenas um "sentido físico" (PP II \$109, p. 214) ou, nos termos de Nietzsche, o ponto-de-vista "para além do bem e do mal" - no qual se reconhece que "não há, de todo, factos morais" (CD Os 'aperfeiçoadores' da humanidade 1).

(b) A partir de Humano, demasidamente humano, um dos principais focos da obra publicada de Nietzsche é a rejeição da própria ideia de metafísica — ou seja, de uma verdade metafísica, de um "mundo verdadeiro", da "coisa-em-si" etc. Na Genealogia da Moral, a sua crítica da metafísica é essencialmente uma crítica da vontade que está por detrás da metafísica: a "vontade de verdade". Em GM III 27, Nietzsche cita o Livro V da Gaia Ciência e o elogio, que nele havia feito, do espírito veraz de Schopenhauer. No contexto desta auto-citação, sustenta que a sua própria filosofia é o momento da história do pensamento europeu em que a "vontade de verdade" se torna auto-referencial e auto-crítica: o momento em que o espírito veraz, a veracidade (Wahrhaftigkeit) já não se limita a abolir "a mentira da fé em Deus" - o que havia sido o mérito de Schopenhauer —, mas, ao tornarse auto-referencial, critica os seus próprios pressupostos e tira "a sua mais forte inferência, a inferência contra si própria” (GM III 27). Ao tornar-se auto-referencial, a vontade de verdade acaba por alcançar e realizar o seu "auto-cancelamento" (Selbstaufhebung, GM III 27, KSA 5.410). Uma incondicional "vontade de verdade" já não é possível no momento da história do ocidente em que Nietzsche escreve a sua obra. A própria ideia de "verdade" revela-se agora como sendo apenas mais outro valor criado e projectado pela nossa necessidade de sentido - ou seja, pelo horror vacui da vontade humana -, e portanto parece ser inevitável a mais extrema conclusão niilista: "nada é verdadeiro, tudo é permitido" (GM 24, KSA 5.399; cf. Za IV A sombra, KSA 4.340). De facto, nos últimos cadernos póstumos, é justamente a isto que Nietzsche chama o "niilismo extremo": "Que não há verdade; que não há uma natureza absoluta das coisas, não há "coisa em si" isto mesmo é um niilismo, e de facto o mais extremo" (NL 1887 9[35], KSA 12.350351).

E, contudo, este tema é bastante mais complexo do que tudo isto sugere. A radicalização do niilismo de Schopenhauer é apenas um lado da filosofia de Nietzsche: o outro lado é a rejeição dos valores de Schopenhauer e, na verdade, do niilismo como um sistema de valores "decadentes". Na obra publicada, Nietzsche nunca se apresenta como niilista, e verifica-se mesmo que a palavra "niilismo" e a expressão "valores niilistas" têm sempre um sentido pejorativo na obra publicada. Isto é claro quando, por exemplo, Nietzsche escreve que a filosofia de Schopenhauer é "uma filosofia niilista que inscreveu a negação da vida no seu escudo" (AC 7) - pois a "afirmação da vida" é uma parte crucial do projecto de Nietzsche. Nas raras ocasiões em que Nietzsche se apresenta como "um niilista", 15

${ }^{15}$ Tal ocorre sobretudo nas cartas. Stegmaier (2016: 35) destaca quatro cartas importantes: a Heinrich Köselitz, 13 de Março de 1881, Nr. 88, KSB 6.68; a Erwin Rohde, Maio de 1887, Nr. 852, KSB 8.80; a Heinrich Köselitz, Novembro de 1887, Nr. 948, KSB 8.192; a Elisabeth Förster, 31 de Março de 
quer dizer certamente o mesmo que diz em Ecce Homo quando se descreve como "um decadente" (EH Sábio 1-2), ou seja, como alguém que é filho do seu tempo e pertence, portanto, ao Zeitgeist pós-schopenhaueriano da décadence. Mas este Zeitgeist é, por sua vez, algo que Nietzsche descreve em termos, no mínimo, ambivalentes (e não de adesão). Todo o "bom europeu" é "decadente", a elite cultural do tempo de Nietzsche - "de São Petersburgo a Paris, de Tolstói a Wagner" (AC 7) - é "decadente" e "niilista”, e também Nietzsche o é. Mas, por outro lado, ser decadente é ser "doente" (e.g. CW 5), a décadence designa a corrupção dos instints animais do ser-humano (AC 6) - a condição na qual um animal deixou de querer a sua saúde, e agora "escolhe, prefere coisas que o prejudicam” (AC 6). Assim, na obra publicada Nietzsche associa a décadence e o niislimo ao ascetismo schpenhaueriano (lembre-se a definição que Schopenhauer dá de ascetismo: "a quebra deliberada da vontade por meio de uma recusa do agradável e uma procura do desgradável”, WWV I \$68, p. 463), à compaixão schpenhaueriana, à vontade de negar a vida, à hostilidade da vida contra si própria, a toda a "doença" do ser-humano moderno (e.g., CI Expedições 7, AC 7, CW 4-5, NW Onde Wagner pertence) $)^{16}$.

O uso pejorativo da palavra "niilismo" e a associação do niilismo com o ascetismo schopenhaueriano é particularmente claro na Genealogia. Em GM III 14, Nietzsche parece até usar a fórmula "vontade do nada" como uma definição de niilismo, quando escreve: "a 'ultima vontade' do ser-humano, a sua vontade do nada, o niilismo” (GM III 14, KSA 5. 368). No Prefácio, sugere algo de semelhante, embora com uma nuance. Aqui, parece conceber o niilismo como algo que irá resultar da vontade do nada num futuro próximo. Nietzsche pergunta-se se o facto de a história da moral ter culminado na "moral da compaixão" de Schopenhauer será, para a Europa, "a passagem para um novo Budismo* para um Budismo para Europeus? para - o niilismo?" (GM Prefácio 5).

Mas, sendo assim, levanta-se novamente a questão de saber o que significa "niilismo" para Nietzsche. Claramente não se trata apenas do sentimento de falta de sentido que resulta da morte de Deus. Se o niilismo é de algum modo o mesmo que a vontade do nada, então é pelo menos tão antigo como Platão e a sua criação de um "mundo verdadeiro". E não há dúvida de que Nietzsche se refere frequentemente ao Platonismo e ao Cristianismo como sendo formas de niilismo (e de decadência, de adoecimento do animal homem etc.). Na verdade, considera os valores de todas as formas do ideal ascético valores niilistas. Mas como pode isto ser assim? O niilismo vem, afinal, antes ou depois da morte de Deus? Como pode o ideal ascético ser niilista? Como pode Nietzsche caracterizá-lo como niilista e, ao mesmo tempo, sustentar que tal ideal dá (tem dado) sentido à vida humana e ao sofrimento humano?

1888, Nr. 1011, KSB 8.281. Cf. também NL 1887-88 11[411], KSA 13.190, and NL 1888 16[32], KSA 13.492. Pace Stegmaier (2016b: 388), esta última nota póstuma apenas confirma a minha tese: a de que Nietzsche associa a palavra "niilismo" a "uma vontade de dizer não" (literalmente "uma vontade de não"), com a qual ele não se identifica (ou com a qual se identifica apenas no sentido em que há também nele um lado "doente", "decadente" que, no entanto, ele preferiria superar).

${ }^{16}$ Cf. Sommer (2012, ad loc.; e 2013, ad loc.). 
Uma resposta possível a estas perguntas consiste em sustentar que a palavra "niilismo" tem vários sentidos para Nietzsche. Segundo Paul van Tongeren (2017, p. 298), "o niilismo tal como Nietzsche o concebe tem três sentidos: é (numa ordem cronológica invertida) (3) a corrosão da (2) estrutura protectora que foi construída para esconder (1) o absurdo da vida e do mundo. O niilismo-1 é por vezes referido como 'pessimismo grego'; trata-se da natureza caótica do mundo, a sua falta de sentido, bem como do reconhecimento disso na cultura pré-socrática. O niilismo2 é a forma de Nietzsche se referir à história da cultura europeia desde Sócrates e Platão até ao século dezanove; e o niilismo-3 refere-se ao que está a acontecer desde então, ou seja, àquilo a que Nietzsche dá por vezes o nome de 'morte de Deus', o que descreve como a história dos séculos que virão, o niilismo em relação ao qual faz todas as distinções que são conhecidas (entre niilismo activo e passivo, completo e incompleto etc)" (tradução nossa).

Porém, se levarmos em linha de conta a importância de Schopenhauer para o desenvolvimento do conceito de niilismo em Nietzsche, e se, ademais, considerarmos a aparente equivalência entre "niilismo" e "vontade do nada" na Genealogia, julgo que se pode encontrar unidade nos três sentidos enlencados por van Tongeren - ou seja, pode encontrar-se um sentido básico de niilismo que é comum aos niilismos 1, 2 e 3. (Note-se que, se não se enconrar um sentido básico, então o uso da mesma palavra para designar três coisas distintas deve ser considerado arbitrário).

Tal como sabemos do que vimos acima sobre Schopenhauer, uma vontade do nada é uma vontade de auto-aniquilação, mas, enquanto tal, é também uma vontade que faz da negação deste mundo - da imanência — uma meta, um objecto de desejo: ao querer o nada como meta (como se o nada fosse algo), a vontade vê o que existe - este mundo terreno "com todos os seus sóis e galáxias" - como se fosse "nada" (nihil), ou seja, como algo sem metas, sem sentido, e sem valor (WWV I \$71, p. 484-487). E isto é precisamente o que Nietzsche entende por "niilismo": uma perspectiva é "niilista" se reduz este mundo a nada; os valores de uma cultura, de um povo, de uma religião, de um filosofia, de um indivíduo são "niilistas" se implicam o sentimento de que este mundo é nihil, um mundo sem metas, sem sentido, e sem valor.

Esta interpretação do que significa niilismo para Nietzsche explica por que razão o ideal ascético é niilista. Sem dúvida que o seu sucesso resultou do facto de ele ter dado sentido à vida humana, mas com o custo de ter retirado todo o sentido deste mundo. O ideal ascético desvalorizou este mundo por comparação com um mundo "mais elevado", um mundo "verdadeiro". Paradoxalmente, deu valor ao mundo da imanência tirando-lhe valor, isto é, atribuindo valor a outra coisa, outro mundo, um mundo transcendente de "valores mais elevados", uma imagem do nada projectada como objecto de desejo. Ao satisfazer o horror vacui da vontade humana dando ao mundo imanente um propósito transcendente, o ideal ascético operou, ao mesmo tempo, um tipo particular de redução do mundo imanente a nada.

Assim, a diferença entre o niilismo do ideal ascético e o niilismo que resulta da morte de Deus é a diferença entre um niilismo mascarado e um niilismo nu. O 
ideal ascético não apagou a falta de metas, de sentido e de valor do mundo imanente - apenas mascarou toda essa falta projectando "valores mais elevados" num "outro mundo que não o da vida, da natureza e da história" (GC 344). Em GM III 14, Nietzsche destaca o niilismo mascarado do ideal ascético como sendo representativo de toda a história da redução do mundo imanente a um nada no Ocidente; no Prefácio, destaca como representativa dessa mesma história uma forma futura do niilismo nu - um possível clímax, por assim dizer, dessa história (e de certa forma também um regressao ao "pessimismo grego", de novo com o perigo da queda num "niilismo suicidário"). Mas, pace van Tongeren, o niilismo, em todas as suas formas históricas, significa sempre o mesmo: a redução do mundo da imanência a um nada. ${ }^{17}$

Como Nietzsche tenta contrariar e mudar esta história - ou como tenta lutar pela "afirmação da vida" e contra a decadente e niilista negação schopenhaueriana da vida - é uma questão decisiva que não cabe, porém, neste artigo.

\section{REFERÊNCIAS BIBLIOGRÁFICAS}

CONSTÂNCIO, João. On Consciousness. Nietzsche's departure from Schopenhauer. Nietzsche-Studien, 40, p. 1-42, 2011.

2013.

Arte e niilismo: Nietzsche e o enigma do mundo. Lisboa: Tinta-da-china,

On Nietzsche's conception of Philosophy in Beyond Good and Evil: Reassessing Schopenhauer's relevance. In: BORN, M. E. e PICHLER, A. (eds.). Texturen des Denkens: Nietzsches Inszenierung der Philosophie in Jenseits von Gut und Böse'. Berlin/Boston: de Gruyter, 2013b. p. 145-164.

Nietzsche on Nihilism (eine unersättliche Diskussion?). In: BERTINO, A. et al. (Eds.). Zur Philosophie der Orientierung. Berlin/Boston: de Gruyter, 2016. p. 83-100.

Nietzsche and Schopenhauer: On Nihilism and the Ascetic 'Will to Nothingness'. In: SHAPSHAY, Sandra (Ed.) The Palgrave Schopenhauer Handbook. Bloomington: Palgrave Macmillan/Springer, 2017. p. 425-446.

CONSTÂNCIO, João; BRANCO, Maria João Mayer; RYAN, Bartholomew (Eds.). Nietzsche and the Problem of Subjectivity. Berlin/Boston: de Gruyter, 2015.

CONSTÂNCIO, João; Sousa, Luis de. Nietzsche's Relation to Schopenhauer. Nietzsche-Studien, 43, p. 294-301, 2012.

\footnotetext{
${ }^{17}$ No meu livro, Arte e niilismo: Nietzsche e o enigma do mundo (Constâncio 2013), exploro esta interpretação do sentido de "niilismo" na obra de Nietzche. Cf. também Constâncio (2016) para uma interpretação das diferentes formas históricas do niilismo reconhecidas por Nietzsche. Note-se que Stegmaier (2016, pp. 28-42) tem razão em sustentar que Nietzsche nunca formulou de facto o seu projecto filosófico como a tentativa de uma "superação do niilismo". Mas, pace Stegmaier, não deixa por isso de ser verdade que Nietzsche apresenta explicitamente a sua filosofia como fazendo parte de uma "luta contra o niilismo" (NL 1886, 5[50], KSA 12.202; NL 1886, 7[31], KSA 12.306).
} 
JANAWAY, Christopher. Beyond Selflessness: Reading Nietzsche's Genealogy. Oxford: Oxford University Press, 2007.

Schopenhauer's Christian Perspectives. In: SHAPSHAY, Sandra (Ed.). The Palgrave Schopenhauer Handbook. Bloomington: Palgrave Macmillan/Springer, 2017. p. 351-372.

LEITER, Brian. Nietzsche on Morality. 2 ${ }^{\underline{a}}$ ed. London and New York: Routledge, 2015.

MAY, Simon. Nietzsche's Ethics and his War on Morality. Oxford: Oxford University Press, 2017. (1 $1^{a}$ edição: 1999)

NIETZSCHE, Friedrich. Sämtliche Werke. Kritische Studienausgabe in 15 Bänden. COLLI, Giorgio e MONTINARI, Mazzino (Eds.). Munich/Berlin/New York: DTV/De Gruyter, 1980 (citado como KSA).

. A gaia ciência (citado como GC).

- Crepúsculo dos ídolos (citado como CI). . Ecce Homo (citado como EH). . Humano, demasiadamente humano (citado como HH). . Nietzsche contra Wagner (citado como NW).

. O Anti-Cristo (citado como AC).

. O caso Wagner (citado como CW).

. O nascimento da tragédia (citado como NT).

. Para além do bem e do mal (citado como BM).

- Para uma genealogia da moral (citado como GM; fez-se uso parcial da tradução de José Miranda Justo. Lisboa: Relógio D’Água, 2000; as demais traduções de textos de Nietzsche e Schopenhauer são do autor do artigo).

PIPPIN, Robert B. Nietzsche, Psychology, \& First Philosophy. Chicago \& London: The University of Chicago Press, 2010.

REGINSTER, Bernard. The Affirmation of Life. Nietzsche on Overcoming Nihilism. Cambridge, Massachussetts and London, England: Harvard University Press, 2006.

SALAQUARDA, Jörg. Der Antichrist. Nietzsche-Studien 2, p. 91-136, 1973.

Die Deutung der Welt. Jörg Salaquardas Schriften zu Arthur Schopenhauer (Beiträge zur Philosophie Schopenhauers Band 8). BROESE, Konstantin; KOßLER, Matthias; SALAQUARDA, Barbara (Eds.). Würzburg: Königshausen \& Neumann, 2007.

SCHOPENHAUER, Arthur. Die Welt als Wille und Vorstellung I, In: HÜBSCHER, A. (Ed.). Arthur Schopenhauer, Sämtliche Werke. Wiesbaden, Brockhaus, 1946-1950, vol. 2, 1949 (citado como WWV I). 
Die Welt als Wille und Vorstellung II. Vol. 3. In: HÜBSCHER, Arthur (Ed.). Arthur Schopenhauer, Sämtliche Werke. Wiesbaden: Brockhaus, 1946-1950 (citado como WWV II).

. Die Grundlage der Moral. Vol. 4. In: HÜBSCHER, Arthur (Ed.). Arthur Schopenhauer, Sämtliche Werke. Wiesbaden: Brockhaus, 1946-1950 (citado como GrM).

Parerga und Paralipomena II. Vol. 7. In: HÜBSCHER, Arthur (Ed.). Arthur Schopenhauer, Sämtliche Werke. Wiesbaden: Brockhaus, 1946-1950 (citado como PP II).

SOLL, Ivan. Schopenhauer, Nietzsche, and the Redemption of Life. In: JANAWAY, Christopher (Ed.). Willing and Nothingness. Schopenhauer as Nietzsche's Educator. Oxford: Clarendon Press, 1998. p. 79-115.

SOMMER, Andreas Urs. Kommentar zu Nietzsches Der Fall Wagner, GötzenDämmerung. Historischer und kritischer Kommentar zu Friedrich Nietzsches Werken. Herausgegeben von der Heidelberger Akademie der Wissenschaften, Band 6/1. Berlin/Boston: De Gruyter, 2012.

- Kommentar zu Nietzsches Der Antichrist, Ecce homo, DionysosDithyramben, Nietzsche contra Wagner. Historischer und kritischer Kommentar zu Friedrich Nietzsches Werken, Herausgegeben von der Heidelberger Akademie der Wissenschaften, Band 6/2. Berlin/Boston: De Gruyter, 2013.

STEGMAIER, Werner. Orientierung im Nihilismus - Luhmann meets Nietzsche. Berlin/Boston: De Gruyter, 2016.

Philosophie der Orientierung. Fragen und Antworten. In: BERTINO, Andrea et al. (Eds.). Zur Philosophie der Orientierung. Berlin/Boston: de Gruyter, 2016b. p. 376-408.

VAN TONGEREN, Paul. Het Europese nihilisme. Friedrich Nietzsche over een dreiging die niemand schijnt te deren. Nijmegen: Vantilt, 2012.

Question or Answer? Kant, Nietzsche, and the practical commitment of Philosophy. In: CONSTÂNCIO, João e BAILEY, Tom (Eds.). Nietzsche's Engagements with Kant and the Kantian Legacy, Vol. II: Nietzsche and Kantian Ethics. London: Bloomsbury, 2017.

Recebido em: 06-09-2018

Aceito para publicação em: 06-11-18 